\title{
Problematizar la memoria en América Latina: nuevas indagaciones a los estudios de la violencia política
}

Víctor Ramos Badillo

Universidad Nacional Federico Villarreal

\section{Lucero de Vivanco \& María Teresa Johansson (eds.). Pasados contemporáneos. Acercamientos} a los derechos humanos y las memorias en Perú y en América Latina. Madrid: Iberoamericana/ Verveurt, 2019. 336 págs.

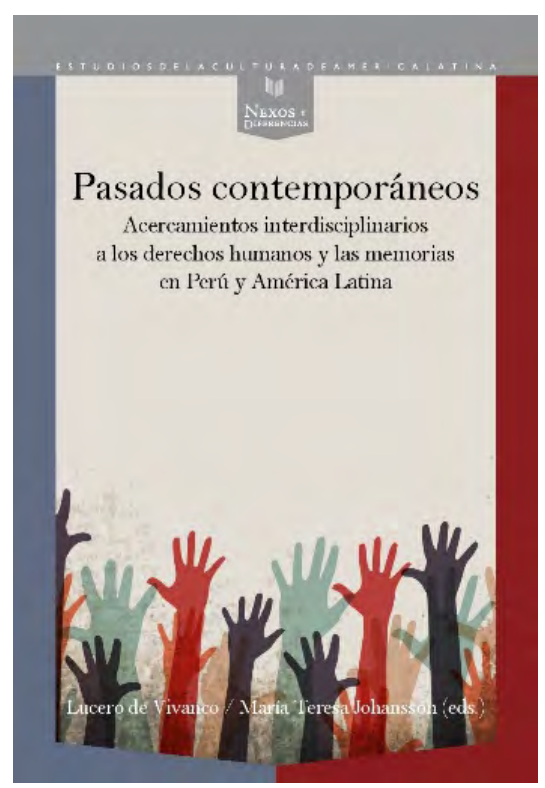

El contexto del siglo XX en las sociedades latinoamericanas fue uno de los más convulsos, puesto que emergieron distintos procesos sociales y políticos que reconfiguraron y alteraron el marco simbólico por donde se encaminaba el continente. Golpes de estado, dictaduras y conflictos armados fueron tres constantes que atravesaron distintos países de América Latina, lográndose con ello visibilizar las contradicciones internas en cada sociedad, a la vez que se mostraban con mayor claridad las brechas de clase y raza dentro de cada una. Ahora bien, pese a que ya transcurrieron años o décadas desde aquel entonces, el imaginario actual sigue insistiendo con el pasado, recordándonos que la herida aún permanece abierta. Esto lo notamos perfectamente en el escenario político y cultural contemporáneos, donde se puede dar cuenta de la importancia de activar o silenciar recuerdos que permiten hilar el pasado con el presente en una relación compleja, puesto que cada uno de estos será interpelado con el fin de obtener nuevas respuestas y preguntas sobre lo acontecido en los estado-nación en América Latina durante la violencia política del siglo XX.

Retomando esta última idea es que Pasados contemporáneos, libro editado por Lucero de Vivanco y María Teresa Johansson, propone actualizar las investigaciones sobre la memoria en este continente, en una exploración que transita entre lo estético y lo político, ampliando así las perspectivas de los estudios que ya han sido llevados a cabo en el mismo eje temático. Este libro, si bien toma en cuenta distintos contextos nacionales, podemos enmarcarlo dentro de producciones críticas peruanas que transitan por una ruta similar. Allí tenemos libros como Lo real es horrenda fábula. Acercamientos, desde Lacan y otros, a la violencia política en la literatura peruana (2019), editado por Paolo de Lima, donde un conjunto de autores busca problematizar las huellas del conflicto armado en la poesía y narrativa peruana; también Dando cuenta: estudios sobre el testimonio de la violencia política (1980-2000) (2016), editado por Francesca Denegri y Alexandra Hibbett, 
Victor Ramos Badillo

quienes reúnen investigadores para analizar discursos testimoniales que están atravesados por el trauma del conflicto armado peruano.

Pasados contemporáneos se construye entonces sobre el concepto de "memoria". Como veníamos mencionando, la constitución de las sociedades latinoamericanas contemporáneas no es ajena al tiempo pasado, puesto que la dimensión político-social aún evidencia diferencias ideológicas bien marcadas. De este modo, la memoria se vuelve un concepto difuso, ya que en ella pueden caber desde nociones reivindicativas de las voces marginadas, hasta paradigmas conservadores que niegan la "otra" historia, con el fin de depurar la violencia que produjo el aparato policial. Como vamos notando, posicionarse como crítico implicará tareas exigentes para desanudar todo el contexto que rodea a cada situación particular, con un propósito de revertir los saberes comunes que se han instalado (y continúan instalándose) en el presente. Para lograr dicho objetivo, se han reunido propuestas metodológicas interdisciplinarias, con lo cual se logra actualizar las lecturas de la crítica literaria latinoamericana. De ahí que la publicación de este libro haya sido necesaria, ya que al análisis cultural se añade el marco temporal-espacial, así como también las controversias que surgieron alrededor del objeto de estudio seleccionado.

El libro está organizado en siete capítulos, cada uno conformado por dos artículos, a excepción del cuarto y séptimo, en los cuales se recogen tres. Casi la primera mitad del libro (los tres primeros capítulos) se encaminan por una perspectiva social o jurídica del contexto peruano, colombiano y chileno, remarcándose, en la mayoría de ellos, el concepto de "justicia transicional". Dentro de esta sección, podemos destacar el artículo "Colombia: tratamiento del pasado, memoria y construcción de la paz", de Elizabeth Lira, y "Memorias negadas: el proceso político peruano de la justica transicional en Perú", de Iris Jave. El primero de estos reconstruye la historia colombiana y la mirada que tuvo dicha sociedad sobre su propio conflicto armado, llegando la autora a preguntarse si los resultados del plebiscito de 2016 mostraron el desinterés de los colombianos, puesto que un gran porcentaje no ejerció el voto, o si más bien esto tiene que ver con el hecho de callar lo que se conoce de parte de los sujetos que atravesaron la experiencia de la violencia política y pese a ello decidieron no votar. El segundo artículo retoma el caso de la violencia política peruana y de cómo el poder judicial en dicho país aún se resiste a condenar a los miembros militares que participaron del conflicto. La disposición jurídica que se adoptó (y se adopta todavía) tiene que ver con la "memoria de la salvación", como menciona la autora, aquella que justifica la violencia estatal puesto que "redimió" a la sociedad de un peor genocidio.

La segunda mitad del libro ahonda en el análisis de la producción cultural en países como Perú, El Salvador, México, Colombia, Argentina y Chile. Entre los artículos más resaltantes se encuentran "La problemática centralidad de la víctima en la memoria cultural peruana", de Alexandra Hibbett, "Narrar la infamia: imagen y escritura para contar la violencia de la historia", de Ana María Amar, y "Fotografiar la propia muerte: las últimas fotografías de Willy Reto en Uchuraccay", de Víctor Vich. El primer artículo mencionado analiza la figura de la víctima en algunas obras literarias, teatrales y 
cinematográficas peruanas que discuten el tema del conflicto peruano. Para ello, la autora se centra en el proceso de producción, circulación y recepción de la obra, puesto que no está exenta de mediaciones sociales que la (sobre)determinan. Con esto se logra visibilizar que las producciones actuales toman como eje principal la figura de la víctima con el fin de generar vínculos emotivos, mas no se problematiza el proceso histórico-social que la rodea. El segundo artículo apuesta por un ejercicio crítico todavía pendiente para los estudios literarios: la representación de los vencidos o derrotados. Ana María Amar, analizando la novela Tríptico de la infamia, de Pablo Montoya, propone que el poder político de lo estético permite "pensar la violencia, la guerra y la destrucción" (p. 220). Con esto, la autora busca aunar la dimensión ética con la política desde la representación estética. Víctor Vich, por su parte, analiza las fotografías de un periodista que murió asesinado por comuneros ayacuchanos, quienes confundieron a él y a sus colegas con senderistas. Las fotos de los últimos minutos de Willy Reto y los demás periodistas, al decir del autor, ponen en cuestión la claridad de la memoria, puesto que se sitúan en la frontera vida-muerte, con lo que se muestran vacíos o inconsistencias en aquel concepto.

Lo resaltante del libro son las formas de problematizar la memoria desde diversas perspectivas académicas, logrando conectar historia, política y sociedad desde teorías contemporáneas para comprender mejor los contextos de violencia política en América Latina. Sin embargo, como podemos notar, todos los análisis se inscriben desde un marco legal económico político. La gran pregunta que deberíamos plantearnos es qué fue de las memorias subterráneas de aquellos que entregaron su vida por un modo de vida distinto. Con esta intervención crítica no se trataría de elevarlos a la condición de mártires, sino de pensar cómo aquellas causas perdidas, que movilizaron a las masas militantes latinoamericanas, pueden activar horizontes políticos radicalmente distintos. 